\title{
Meeting Differing Learning Styles Of Non-traditional Students In The Second Language Classroom
}

Deborah Gill, (E-mail: djg25@psu.edu), Pennsylvania State University, DuBois

\begin{abstract}
In every classroom a range of learning styles exist. The foreign language classroom at the postsecondary level is no different, with the added component of having students who are traditional (i.e., those just graduated from high school) to those who are non-traditional (i.e., those who have been out of high school for at least a couple of years). The proposed study will discuss ways in which student-centered, active and collaborative learning activities, including the use of technology, can meet different learning styles for both traditional and non-traditional students and provide a successful experience for all.
\end{abstract}

\section{INTRODUCTION}

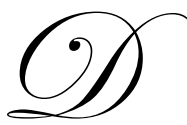

iffering learning styles in a classroom is inevitable. In the language classroom this is no different. Some students will try to focus on grammar, while others will be less motivated by grammar and more enthusiastic when conversing, looking at the big picture. This paper will focus on nontraditional students and how differing learning styles can be met in the second language classroom, what components lead to language learning, and how, through different activities, instructors can help students with different learning styles succeed in learning a second language.

\section{WHAT ARE LEARNING STYLES?}

Learning styles have been defined in many different ways (Felder 1993, Gardner 1998, Kolb 1976, Willis and Kindle Hodson 1999, among others). In general, learning styles refers to the overall approach by which a student learns, i.e., how a student "acquires, retains, and retrieves information" (Felder 1993). This includes (1) cognitive styles; (2) motivation (attitude); (3) seeking situations which are similar to their own language learning strategies; and (4) using and avoiding certain learning strategies. For purposes of this paper, and following Felder 1995, we will break learning styles into five categories:

\footnotetext{
- $\quad$ sensory vs. intuitive;

- $\quad$ visual vs. verbal;

- $\quad$ active vs. reflective;

- $\quad$ sequential vs. global; and

- $\quad$ inductive vs. deductive
}

One learning style does not necessarily preclude another and many students may (and realistically will) possess a number of different learning styles. For example, a sensory learner may also be an active learner, etc.

Students who are sensory learners tend to be methodical in their thinking, preferring facts, data, and detail. A fundamental learning strategy for the sensory learner is memorization and learning and following rules. This may slow them down because they do prefer to not make mistakes. On the other hand, students who are intuitive learners are more imaginative, enjoy concepts, and do not like details. The intuitive learner does not like repetition and does 
not seem bothered by the exceptions to the rules that frequently occur. They are quick but they may make mistakes because they do not pay attention to the detail and rules. Studies done by Moody (1988) and Ehrman and Oxford (1990) showed that language learners tend to be intuitors, citing that "language is by its nature symbolic, which would tend to make it more attractive to intuitors than to the more concrete and literal-minded sensors" (Moody 1988:398).

In the second language classroom, students who are sensory learners tend to use memorization strategies such as flashcards, prefer drill-type activities, and prefer highly-structured classes. On the other hand, the intuitive learner dislikes drills, prefers variety, and is not concerned with the teaching style of the instructor.

Visual learners prefer to have information presented visually, with pictures, flow charts, diagrams, etc., instead of oral or written words. On the other hand, verbal, or auditory, learners prefer oral or written explanations to visual clues.

In the second language classroom, "most language instruction is verbal, involving predominantly lectures, writing in texts and on chalkboards, and audiotapes and CDs in language laboratories" (Felder 1995). By including visual stimulation to the oral and written texts, meeting the needs of both visual and verbal learners is natural and, generally, common in the second language classroom.

The third learning style is that of the active and reflective learner. Active learners prefer having to use -in as authentic a situation as possible - what they are learning, such as whole and small group discussions, role plays, etc. On the other hand, the reflective learner would prefer to think about and reflect upon the subject that they studying. Activities such as answering questions in writing, short writing assignments, etc. are more in line with what the reflective learner would like to do.

In the second language classroom, the active learner learns best through oral activities, small group discussions, etc., while reflective learners are more comfortable when having to answer specific questions in writing and/or write dialogs, compositions, etc.

The fourth learning style is sequential and global learners. Sequential learners prefer small chunks of information and learn in an orderly manner. The global learner does not mind having chunks which might be disconnected; they are able to understand through the whole picture. Therefore, global learners might not do well on tests nor on homework at the start, but once the whole picture is given to them; there will be a large leap in both understanding and performance. The sequential learner will be able to do well on what is currently being studied but at times are unable to connect the whole picture in the end.

With respect to second language learning, Leaver (1986) suggests that those who are left-brain thinkers (the sequential learner) have an easier time with grammatical structures and contrastive analysis of the language, while the right-brain thinkers (the global learners) are better at intonation and rhythm. The sequential learners are comfortable with grammatical analysis, while the global learner prefers less formal instruction, including the unstructured study of the language, i.e., inferring meanings rather than looking every word up in a dictionary.

Finally, the last learning style we will discuss here is the inductive learner versus the deductive learner. The inductive learner observes first and then looks at the rules and theories later. On the other hand, the deductive learner looks at the rules and theories first and then observes within the confines of these rules and theories. Therefore, many students tend to be deductive learners, because of the structure which is provided by looking at a rule and observing within certain boundaries.

Felder (1995:26) proposes that language acquisition and language learning can be paralleled to induction and deduction, respectively. One acquires a language gradually, not necessarily being able to articulate the rules. Since the progression is from specifics to generalizations, acquisition is seen as being inductive. On the other hand, language learning is a "conscious process ... [of] rules of syntax and semantics followed by specific applications of the rules, with corrective feedback reinforcing correct usage and discouraging incorrect usage" (Felder 1995:26). Learning from general to specific suggests a deductive process. Although Krashen and Terrell (1983:18) held that 
acquisition can only occur in natural settings, they also state that "despite our conclusion that language teaching is directed at learning and not acquisition, we think that it is possible to encourage acquisition very effectively in the classroom" (Krashen \& Terrell 1983:27). Therefore, inductive and deductive processes are complementary in nature instead of competitive. If a student is to achieve complete command of a language, a combination of inductive and deductive processes will be used: that is, a student will use inductive processes to speak fluently (acquisition) and deductive processes (learning) to be able to write grammatically correct compositions, etc.

\section{THE SECOND LANGUAGE CLASSROOM}

Now that we have looked at five different learning styles, what are the effects of these learning styles on the Community College (two year institution) second language classroom?

The community college student body is made up of approximately $41 \%$ nontraditional students. The term "nontraditional student" has been defined in many different ways. The definition of a nontraditional student that we will use here is a student over 23 years of age who has been out of high school for five years or more or who has served in the United States Armed Forces for four or more years.

Nontraditional students have different needs, different characteristics, and are motivated (positively and negatively) by a number of different factors which differ from that of their traditional student counterpart.

Looking at the nontraditional student, a number of characteristics are apparent. They:

- $\quad$ are autonomous and self-directed;

- $\quad$ are goal oriented;

- $\quad$ are relevancy oriented (problem centered) — they need to know why they are learning something;

- $\quad$ are practical and problem-solvers; and

- $\quad$ have accumulated life experiences

(Cranton 1992:13-14)

It is well-known that, in order for a student to learn a language and to become culturally competent, the student must be motivated and have a purpose for wanting to learn a language and about different cultures. Gardner and Lambert (1959) distinguished between two types of motivation: integrative and instrumental. Integrative motivation deals with a learner's positive attitude toward the target language group and its culture, including meeting and interacting with other members of the community. On the other hand, instrumental motivation deals with learning a language for a purpose, such as getting a job, passing an exam, etc. According to Cantor (1992), nontraditional student motivation is different than that of a traditional student. The nontraditional student is motivated:

- $\quad$ to make or maintain social relationships;

- $\quad$ to meet external expectations--the boss says you have to upgrade skill $\mathrm{X}$ to keep your job;

- $\quad$ to learn to better serve others -- managers often learn basic First Aid to protect their employees;

- $\quad$ for professional advancement;

- $\quad$ to escape or for stimulation; and

- for pure interest

(Cantor: 1992: 37-38) include:

However, in addition to these motivations, nontraditional students also have a number of barriers. These

\footnotetext{
- $\quad$ many other responsibilities (families, careers, social commitments);

- $\quad$ lack of time;

- $\quad$ lack of money;

- $\quad$ lack of child care;
} 
- $\quad$ scheduling problems;

- $\quad$ transportation problems;

- $\quad$ insufficient confidence; or

- $\quad$ having to learn, but not interested or ready

(Cantor 1992:39)

Motivation is also key to the success of the nontraditional student in the second language classroom. In order to observe the motivation and language attitude of nontraditional students, a small pilot study of nontraditional students was done during the Academic Year 2003-2004. At the beginning and end of each semester, students were given a Language Attitude Questionnaire in which questions related to the use of technology (an ebook, web activities, chats, virtual communities and collaborations, etc.) are part. The purpose of this questionnaire was to observe attitude toward language learning as well as motivation to gain language proficiency and cultural competence. Below are seven questions which were analyzed:

1. I enjoy lessons on the computer.
Strongly Disagree
1
$2 \quad 3 \quad 4$
$5 \quad$ Strongly Agree

2. I have used virtual communities, chats, IRC, etc. in classes before and enjoyed it.
Strongly Disagree
1
3
45
Strongly Agree

3. Working and collaborating with others is interesting.
Strongly Disagree
1
2
3
4
$5 \quad$ Strongly Agree

4. It would be/is beneficial to talk with other language learners and native speakers of Spanish.
Strongly Disagree
1
2
34
5 Strongly Agree

5. I prefer using a textbook than talking in class.
Strongly Disagree
$1 \quad 2 \quad 3$
$4 \quad 5$
Strongly Agree

6. I prefer using a textbook and working alone than collaborating with other people.
Strongly Disagree
1
2
$4 \quad 5$
Strongly Agree

3

7. I think it is difficult to work with others collaboratively on line.
Strongly Disagree
1
2
3
4
5
Strongly Agree

Table 1: Comparison of Language Attitude Questionnaires

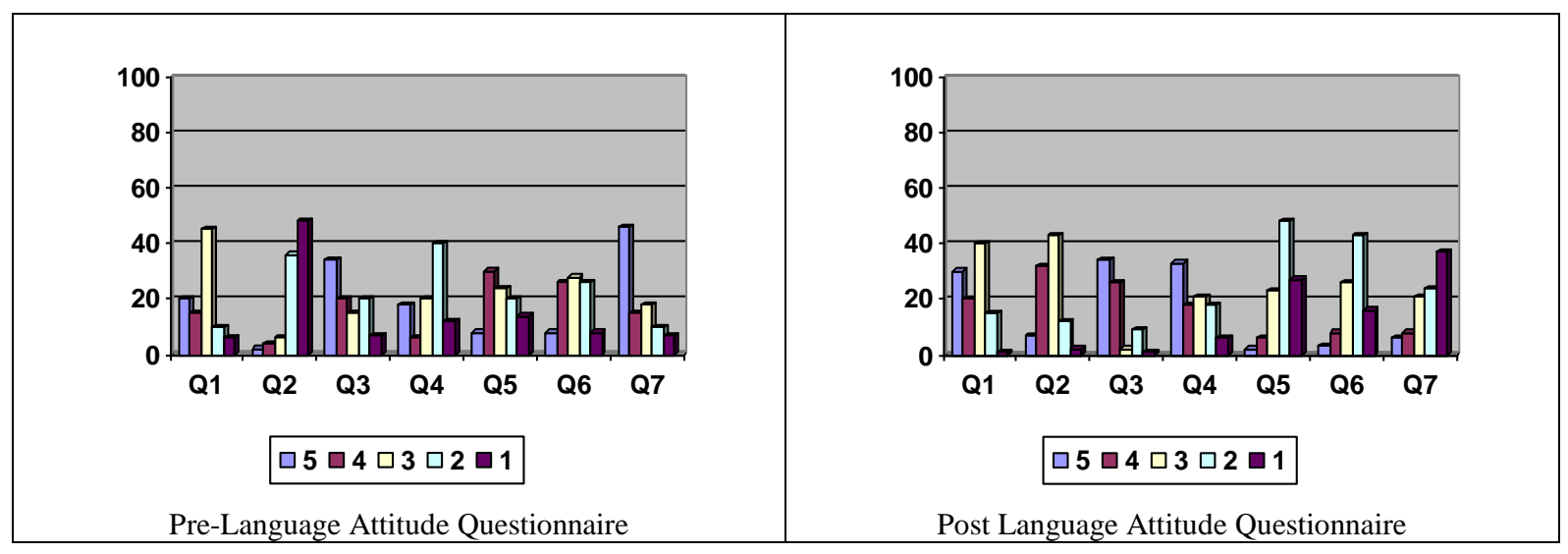


All students in basic language Spanish courses were given the language attitude questionnaire. Of the ninetysix total students, 66 were nontraditional students. Table 1 is a summary of the results of the questions above for the nontraditional students who participated in the study:

Sixty-six students responded to both the Pre- and Post-Language Attitude Questionnaires. The results support the idea that, when given the opportunity to participate in active learning, most students will choose collaborative activities over those in which they are working alone and passively learning.

At the beginning of the semester, overall the nontraditional students noted that they preferred passive learning, i.e., using and reading their textbooks and working alone, to working collaboratively with others. However, at the end of the semester, after working within a virtual community environment on individual activities, collaborative activities with their classmates, and collaborating with native speakers of Spanish, the results showed showed a reversal in that students overwhelmingly preferred to collaborate with others than work alone. Their written comments also demonstrated this point:

- “All Spanish classes should be organized this way! In other classes I've taken, you just memorize and then forget because you aren't using it anymore. This way I have to remember so that I can keep using it!"

- "My partner was awesome! Even if I didn't know a word or how to say something, or if I wrote something that wasn't quite right, he didn't get mad, he just helped me. I've learned some really cool expressions with him!"

- $\quad$ "This was really a challenge, but it was really fun too. I think I learned more Spanish this way even though I wasn't always just reading. And my tests were good too!"

- "I learned a lot. I wish I could have done this in my other classes."

The majority of comments were similar to the ones above, although there were a few students who did not see the experience as positively:

- $\quad$ "I wish we worked more on grammar and had more practice with the verbs. I don't think working with other students helps at all."

- $\quad$ "Working with a native speaker was too stressful. If I wanted to talk with native speakers I would either go to another country to do it or I would go to a chat room. What a waste of time."

- "I was only taking this class because I had to. Why should I have to talk with people I don't know?"

Therefore, the nontraditional student might possess integrative, instrumental, or a combination of integrative and instrumental motivation which will affect the ability to succeed in the second language classroom.

The question, then, is: How can we, as instructors, help students, especially nontraditional students, with different learning styles succeed in the second language classroom? We propose that perhaps this can be accomplished through (1) helping the nontraditional student gain learning strategies and (2) through the types of activities which we provide in our classrooms.

\section{MEETING NONTRADITIONAL STUDENT LEARNING STYLES}

\section{Learning strategies}

Learning strategies have been described as "behaviors used by language learners to enhance the acquisition, storage, retention, recall, and use of new information" (Oxford 1990:36). These strategies can be divided into two types: direct and indirect, both important to succeed in the second language classroom. Direct strategies are involved with language learning itself and involve three main types. First, memory strategies aid in the ability to memorize information and retrieve it, providing the student with an opportunity to begin and eventually build upon the knowledge he/she is learning to become linguistically proficient. Some of these strategies might include making flashcards, using mneumonics, etc. In line with the memory strategies are cognitive strategies, providing students the ability to manipulate and produce language. These strategies might include playing with the language by combining 
elements, using cognates for descriptions, etc. Finally, compensation strategies help to overcome limitations in language knowledge through providing students techniques in which they may express their points through what they know. One of the most common compensation strategies is the use of circumlocution, i.e., using language to be able to explain a word or an idea that is not available to the student.

On the other side are indirect strategies. Although not related directly to language learning, these strategies also are fundamental to the language learning process. While learning a second language to become proficient, metacognitive strategies give a student the ability to organize his/her learning, i.e., to be able to categorize what he/she is learning. Affective strategies deal with the "affects", providing mechanisms for emotions and attitudes. Students learn ways in which to express emotion and show attitude, learn how to recognize emotion within the culture, etc. Finally, social strategies are essential. These strategies facilitate collaboration and learning between individuals.

\section{Types of activities to include}

Keeping in mind the characteristics of the nontraditional student, it is necessary to include a variety of activities in the second language classroom in order to meet the differing learning styles in the second language classroom. These activities should be activities that will combine a number of different learning styles and learning strategies as well as try to motivate students. In the foreign language classroom, communicative, task-based, and content-based activities provide this input. Examples of these activities include:

- $\quad$ Situational contexts. Instead of reading vocabulary lists and/or grammar points and having students follow along, put new vocabulary and/or grammar points into context, i.e., through the use of a situation. Use visuals of some sort (i.e., PowerPoint, photos, authentic materials) within a plausible context (for example, an unforgettable day in your life when you are working on past tense verbs, special days, leisure activities, emotions, etc.). Situational contexts with visual clues can meet a number of different learning styles of students: intuitive, visual, global, inductive)

- "Drill and kill". Provide students with an opportunity to work on vocabulary and grammar through basic drill and kill techniques outside of the classroom. Part of this drill and kill may contain images rather than simply using textual clues. Putting these drill and kill assignments into contextualized situations instead of unconnected sentences provide students with different learning styles ways in which to deal with the material.

- Writing assignments. Provide students an opportunity to think about what they are doing through short writing assignments. This will meet the needs of those students who are reflective. In addition, use writing activities which are collaborative in nature, i.e., a collaborative story set up in a "round robin" situation. This provides students the opportunity to be reflective but at the same time be active. Finally, formal writings provide an opportunity for students to reflect and develop written skills, providing the deductive learner as well as the reflective learner an opportunity to build skills.

- Small group activities. Use thematic discussions of issues presented in a reading for small group interaction. This provides students and opportunity to reflect and actively participate in the target language.

- $\quad$ Collaborative projects. Have students work in collaborative groups with others in the same class, in another class, or with a native speaker of the target language. This provides students an opportunity to develop oral skills. Many different learning styles can be met with this type of activity.

\section{CONCLUSIONS}

Meeting the learning styles in the second language classroom can be accomplished using a variety of teaching methods. Traditional as well as nontraditional students have multiple learning styles and therefore it should be possible to meet some of their needs during every class if the activities during any one class are varied sufficiently to provide opportunities for all learners to have a positive experience and are set up to motivate every student, whether or not he/she is there "because it's a requirement" or because he/she truly has an interest in developing language proficiency and cultural competence. 


\section{REFERENCES}

1. Cantor, J.A. 1992. Delivering Instruction to Adult Learners. Toronto: Wall \& Emerson.

2. $\quad$ Cranton, P. 1992. Working with Adult Learners. Toronto: Wall \& Emerson.

3. Ehrman, M. and R. Oxford. 1990. Adult Language Learning Styles and Strategies in an Intensive Training Setting. The Modern Language Journal. 74:311-327.

4. Felder, R.M. 1993. Reaching for the second tier: Learning and teaching styles in college science education. Journal of College Science Teaching. 23/5:286-290.

5. Felder, R.M. 1995. Learning and Teaching Styles in Foreign and Second Language Education. Foreign Language Annals 28.1/21-31.

6. Gardner, H. 1998. Intelligence in seven steps. In Dickinson, D. ed. Creating the Future: Perspectives on Educational Change. New Horizons for Learning. http://www.newhorizons.org/crfut_gardner.html [12/14/04]

7. Gardner, R. and W. Lambert. 1959. Motivational variables in second language acquisition. Canadian Journal of Psychology 13: 266-272.

8. Kolb, D.A. 1976. Learning Styles Inventory. McBer and Company.

9. Krashen, S. and T.D. Terrell. 1983. The Natural Approach: Language Acquisition in the Classroom. Oxford: Pergamon Press.

10. Leaver, B.L. 1986. Hem isphericity of the Brain and Foreign Language Teaching. Folio Slavica. 8:2-15.

11. Miller, S. 2000. Learning Styles Survey. http://www.metamath.com/lsweb/fourls.htm [12/14/04]

12. Moody, R. 1988. Personality Preferences and Foreign Language Learning. The Modern Language Journal. 72:389-401.

13. Oxford, R. 1990. Language Learning Strategies and Beyond: A Look at Strategies in the Context of Styles. Shifting the Instructional Focus to the Learner. Ed. Sally Magnan. Middlebury, VT:Northeast Conference Reports, 1990:35-55.

14. Willis, M. and V. Kindle Hodson. 1999. Discover your child's learning style. Prima Publishing. 
NOTES 